\title{
„DUMNEZEU (...) NU LOCUIEȘTE ÎN TEMPLE FĂCUTE DE MÂINI"?! (FA 17, 24)
}

\section{Traian FLOREA*}

\begin{abstract}
God (...) does not dwell in temples made with hands"?! (Ac 17, 24) ${ }^{1}$. This research addresses the Saint Paul's statement: "God (...) does not dwell in temples made by hands" - an assertion told in Athens, in front of idolatrous pagans. The approach of this assertion, from an exegetic perspective, shows how the meaning of this claim is complemented by the meaning of other passages of Sacred Scripture of both the Old and the New Testa ment. The literal meaning of the statement is evaluated in harmony with the philoca lic understanding, especially of the Saint Maximus the Confessor, but also with the understanding of the other researchers of the Holy Scriptures.This consensus emphasize the unitary way in which is meant to be understood a worship place, both from the perspective of the exegesis of the biblical text and from the point of contemplation in the spirit of prayer. The present study shows that the Apostle Paul's percutaneous statement - "God does not dwell in temples made by hands" - does not eliminate the role of a worship place, but highlights the value of the Church and its significance as a "spiritualTemple", where God lives and is worshiped.
\end{abstract}

Keywords: temple, worship place, Areopagus, typological, the Church.

\section{Preliminarii}

Afirmaţia Sf. Ap. Pavel: „Dumnezeu (...) nu locuiește în temple făcute de mâini” face parte din discursul ținut în Areopagul Atenei. Cuvântarea din Atena aduce în atenție întâlnirea dintre Evanghelie și filozofie, deoarece Atena era considerată ,capitala simbolică a culturii””

*PhD Student, Faculty of Orthodox Teology at „Babeş-Bolyai”” University, Cluj-Napoca, Romania.

${ }^{1}$ Studiu redactat sub îndrumarea Pr. Prof. Univ. Dr. Stelian Tofană, care şi-a dat acordul pentru publicare.

${ }^{2}$ Gérard Rossé, Faptele Apostolilor, trad. Silvestru-Robert Bălan, Iași, Edit. Sapientia, 2016, p. 597. 
iar, prin acest discurs, propovăduirea Evangheliei se întâlnește cu filozofia antică.

Prezentul studiu, pornind de la premisa tradițională că discursul aparține Sf. Ap. Pavel, abordează a firmația acestuia: „Dumnezeu (...) nu

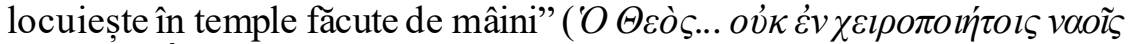
$\kappa \alpha \tau o$ $\kappa \varepsilon i ̃)$. În prezentul studiu, arătând semnificația aceastei afirmaţii, atât din perspectiva exegetică, cât şi sub aspectul înțelegerii duhovnicești și practice, ne propunem să evidențiem importanța Bisericii ca Templu spiritual, dar, în același timp, să identific ăm şi rolul unuilocaș de închinare.

\section{O perspectivă exegetică}

\subsection{Tradiția afirmației: „Dumnezeu (...) nu locuiește în temple făcute de mâini"}

Afirmația: „Dumnezeu (...) nu locuiește în temple făcute de mâini” nu este una inedită. Astfel, în Vechiul Testament, prin cuvintele: „Şi cine poate să-I zidească Lui templu, când cerul și cerurile cerurilor nu-L încap?" (2 Par. 2, 6), regele Solomon recunoaște cu smerenie cât de mică este opera pe care vrea s-o facă, în comparație cu măreția lui Dumnezeu. Mai târziu, profetul Isaia reia ideea lui Solomon, iar prin întrebarea retorică: „Ce fel de casă Îmi veți zidi voi (...)?” (Is. 66, 1) pune accent pe nemărginirea lui Dumnezeu, care vine să relaționeze cu omul.

În Noul Testament, Sf. Arhid. Ștefan înțelege cuvintele Profetului Isaia în termenii: „Cel Preaînalt nu locuiește în temple ${ }^{3}$ făcute de mâini” (Fap. 7, 48). Se conturează, așadar, o linie de transmitere a tradiției solomonice cu privire la relația Dumnezeu-Templu: regele SolomonProfetul Isaia - Sf. Arhid. Ștefan - Sf. Ap.Pavel.

\section{2. „Locuirea” Iui Dumnezeu în temple făcute de mâini?}

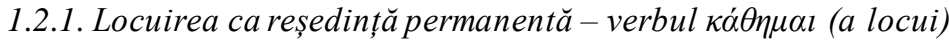

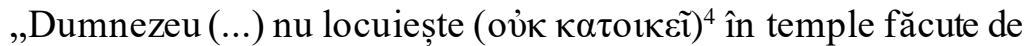
mâini" (Fap. 17, 24) este afirmația Sf. Ap. Pavel. Verbul folosit aici

\footnotetext{
${ }^{3}$ Literal, în cele făcute de mâini.

${ }^{4} E$ vorba de locuire cu sens de reședinţă permanentă/de domiciliu.
} 


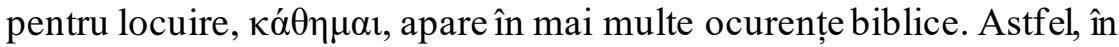
cuvântarea de la Cincizecime, Sf. Ap. Petru citează cuvântul regelui

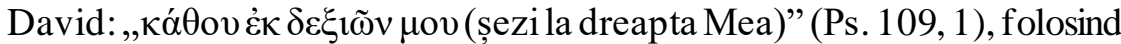

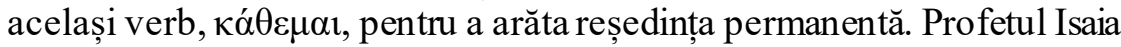

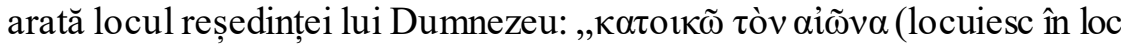
înalt)" (Is. 57, 15).

Dacă pentru unii greci antici locuința zeilor era Olimpul $1^{5}$, pentru concepția multor greci din primul secol locuințele zeilor sunt, prin excelență, templele. Această înţelegere vine, în mod indirect, din afirmația Sf. Ap. Pavel: „Dumnezeu (...) nu locuieşte în temple făcute de mâini”, afirmație ce combate înțelegerea grecilor. Istoricul Ovidiu Drimba spune că „un templu grec era prin definiție «locaşul zeului»»" Din af irmația lui Thales din Milet că ,totul este plin de zei”" acesta se pare că ,,păstrează anumite teme fundamentale din vechile mituri", , Ovidiu Drimba înțelege că Thales „,scotea divinitatea din ambianța sacră a templului’’’. Astfel, se înțelege că pentru majoritatea grecilor locuințele zeilor erau templele, însă filosofii îndrăzneau să gândească adesea contrar opiniei majoritare.

\subsubsection{Locuirea ca părtăşie/comuniune-verbul oiké́ (a locui împreună cu cineva)}

Verbul oíć́ este folosit de Sf. Ap. Pavel pentru a arăta perspectiva spirituală ${ }^{10}$. El vorbește despre ,păcatul care locuiește

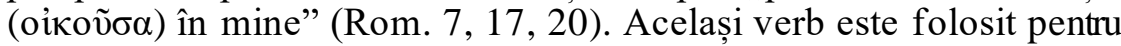
locuirea Duhului, în textul: „Dacă Duhul lui Dumnezeu locuiește (oỉkદ̃) în voi” (Rom. 8, 9, 11). Viețuirea Duhului în credincios face din acesta un templu al lui Dumnezeu, potrivit cuvântului scris de Sf. Ap. Pavel:

5 Potrivit mitului originar, ,apariția Atenei [a avut loc, n. ns.] pe vârful muntelui Olimp’(Mircea ElIADE, Istoria ideilor și credințelor religioase, vol. 1, București, Edit. Ştiinţifică, 1991, p. 278).

${ }^{6}$ Ovidiu DriBma, Istoria Culturii și Civilizației, vol. 1, București, Edit. Științifică și Enciclopedică, 1985, p. 552.

7 Jean-Pierre Vernant, Mit şi gândire în Grecia Antcă, trad. Zoe Petre și Andrei Niculescu, București, Edit. Meridiane, 1995, p. 485.

${ }^{8}$ Ibidem.

${ }^{9}$ Ovidiu Dribma, Istoria Culturii și Civilizației, vol. 1, p. 557.

${ }^{10}$ Verbul oíké $\omega$ este folosit și cu privire la taina căsătoriei (cf. 1 Cor. 7, 12-13). 


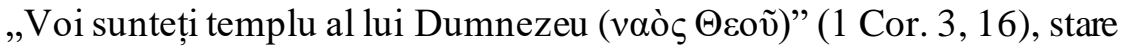

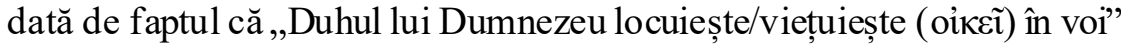
(1 Cor. 3, 16). Folosirea pluralului: în voi, indică atât spre persoane individuale, cât și spre comunitatea Duhului, spre Biserică - Templu divin.

\subsection{Temple făcute de mâini}

Afirmația Sf. Ap. Pavel era că: „Dumnezeu (...) nu locuiește în temple (vooĩs) făcute de mâini”. Aceste clădiri strălucitoare, pe care Apostolul le avea în vedere ${ }^{11}$, provenite atât de la Pericle ${ }^{12}$, cât şi de la Augustus, care ,a construit un templu circular ionic pentru Roma"13, l-au condus pe Sf. Ap. Pavel să afirme despre temple că sunt lucrarea omului. În epoca cetăţii, „templul grec este o locuință: zeul o ocupă”" ${ }^{14}$. Zeul aparține întregii cetăți, pentru că „,aceasta i-a clădit casa" ${ }^{15}$. În discurs, templele, ca operă umană, sunt puse în contrast cu opera divină. Omul a făcut templele și idolii, dar Dumnezeu este autorul și susținătorul întregii creații. De aceea El „nu poate fi cuprins de un templu și nu este reflectat de idoli" ${ }^{16}$.

Logica Apostolului când face această afirmație este una simplă: „Dacă nici măcar Templul din Ierusalim, construit pentru închinarea Dumnezeului lui Israel, nu putea să-L cuprindă, cu atât mai puțin aceste temple strălucitoare ale Acropolei, închinate zeilor care, în realitate, nu erau dumnezei" ${ }^{17}$. Ideea susținută de Sf. Ap. Pavel pare a fi și un ecou filosofic, pe care Apostolul îl sugerează. Astfel, textul atribuit lui Euripide: „Ce casă construită de meșteri ar putea închide forma divină în

${ }^{11}$ În momentul cuvântării, Sf. Ap. Pavel putea vedea în apropiere vechile temple grecești: Partenonul, închinat zeiţei Atena, și Erechteionul.

${ }^{12}$ Parthenonul, templul închinat zeiței Atena, a fostridicat din inițiativa lui Pericle, în sec. V î. Hr. (Ioan M. Stolan, Dicționar religios, București, Edit. Garamond, 1994, (item Partenon), p. 200.)

${ }^{13}$ David W. J. Gill / Conrad GemPF, (eds.), The Book of Acts in Its Graeco-Roman Setting, Grand Rapids, Edit. William B. Eerdmands Publishing Company, 1994, p. 442.

${ }^{14}$ Jean-Pierre Vernant, Mit și gândire în Grecia Antică, p. 485.

${ }^{15}$ Ibidem.

${ }^{16}$ Darell L. Bock, Acts, Grand Rapids, Edit. Baker Academic, 2007, p. 565.

${ }^{17}$ Frederick Fyvie BRUCE, Commentary on the Book of the Acts, Grand Rapids, Edit. Eerdmans Publishing Company, 1980, p. 357. 
interiorul zidurilor ei?"18 aduce o afirmație neechivocă, aceea că divinitatea nu este limitată de materie, ci o transcende.

În această afirmație a Sf. Ap. Pavel, templele sunt numite vaoǐs. Denumirea Templului din Ierusalim, de cele mai multe ori, nu este $v \alpha o \tilde{s}$.

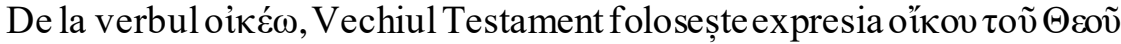
sau oǐkov Kupíov pentru „Casa lui Dumnezeu/Casa Domnului (1 Par. 18, 28, 31; 2 Par. 4, 19); astfel subliniem folosirea predilectă pentru Templul din Ierusalim a cuvântului oî́kov, care are aceeași rădăcină cu verbul oikéc (a viețui). Tot astfel, în Noul Testament, Matei folosește pentru

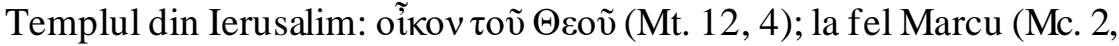
26) şi Luca (Lc. 6, 4). Acesta (Templul din Ierusalim) este templu omenesc, dar un alt templu, ,nu făcut de mână”(Evr.9, 11), este Templul în care a intrat Iisus ca Arhiereu, pentru ispășirea păcatului omenesc.

\section{Locuința lui Dumnezeu. O altă perspectivă a Scripturii}

\subsection{Templul duhovnicesc}

Afirmația: „Dumnezeu(...) nu locuiește în temple făcute de mâini”, ridică în mod legitim întrebarea: Unde este locuinţa Lui?

Unul dintre răspunsuri este acesta: „Sfințenia lui Dumnezeu este cea care constituie singurul sanctuar veritabil - Sfânta Sfintelor, iar pentru a-i exprima transcendența, limbajul omenesc o situează în cer"' ${ }^{19}$, unde este și Hristos. Altfel spus, „locul unde Își desfăşoară acum activitatea arhierească Hristos este cerul propriu-zis”"20, care este „,nemijlocita apropiere de Dumnezeu" 21 . Vorbind despre slujirea arhierească a lui Hristos - „pe întregul ceriu 1-a pus în locul Templului”" 22 - Sf. Ioan Gură de Aur vorbește despre locuința lui Dumnezeu, care este cerul.

${ }^{18}$ EurIPIDES, Fragment 968, apud Frederick Fyvie BRUCE, Commentary on the Book of the Acts, p. 357.

19 Stelian Tofană, Iisus Hristos Arhiereu veșnic - după Epistola către Evrei, ClujNapoca, Edit. Presa Universitară Clujeană, 2000, p. 375.

${ }^{20}$ Ibidem, p. 403.

${ }^{21}$ Erich GRABER, An die Hebraer, Zurich, EKK zum Neuen Testament, 1990, p. 191, apud Ibidem, p. 403.

${ }^{22}$ Ioan Chrisostom, Comentariile sau Explicarea Epistolei Cătră Ebrei, trad. Theodosie Athanasiu, București, Edit. Tipografia Cărților Bisericești, 1923, p. 225. 
Pe de altă parte, potrivit Noului Testament, este evident că Biserica este Templul lui Dumnezeu, iar aceasta nu este zidită de mâna omului, căci Mântuitorul spunea: ,Voi zidi Biserica Mea”(Mt. 16, 18) - învățătură întrezărită de comunitatea de la Qumran prin concepția despre un templu spiritual eshatologic ${ }^{23}$. Referindu-se la metafora trupului (1 Cor. cap. 12), Savatie Baștovoi înțelege că „,adunarea credincioșilor (...) era însăși Biserica” "24, așa cum Sf. Ap. Pavel îi întreba retoric pe corinteni: „Nu știţi că voi sunteți Templul lui Dumnezeu?" (1 Cor. 3, 16), completând cu afirmația: „Căci sfânt este Templul lui Dumnezeu (vaò sunteți voi” (1 Cor. 3, 17). Folosind metafora Templului, Sf. Ap. Pavel îi cheamă pe corinteni să înțeleagă natura Bisericii, care ,nu este o construcție oarecare, ci este chiar Templul lui Dumnezeu"25, idee completată de Sf. Ap. Petru cu precizarea naturii acestei case, zidită din

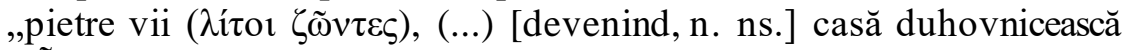

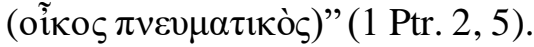

Afirmația transferată la fiecare individ poate însemna că Dumnezeu ,«nu locuiește în biserici făcute de mâini», ci în sufletul omenesc"26. Sf. Maxim Mărturisitorul spune, tot ca o aplicare la individ, că „,cel mai potrivit locaș al lui Dumnezeu este numai mintea curată’27. În contextul literaturii grecești, în care zeița Atena ,își recomandă” înţelepciunea: „Eu între zei pe lume sunt vestită pentru agerimea minții și prin iscusința mea"28, iar, potrivit unor legende, Atena iese din fruntea lui Zeus, printr-o lovitură de bardă ${ }^{29}$, aceasta va fi cunoscută în timpul

${ }^{23}$ Cairo Geniza Documents of the Damascus Convenanters (CDC), iii. 9, apud James D. Douglas (ed.), The New Bible Dictionary, London, Edit. The Inter-Varsity Fellowship, 1962, (item Temple), p. 1248.

${ }^{24}$ Savatie BAștovoi, Pietrele vorbesc, București, Edit. Cathisma, 2014, p. 27.

25 Cristian-Flavius Terinte, Viața Bisericii conform metaforelor pauline, Oradea, Edit. Societatea Biblică din România, 2010, p. 226.

26 Teofilact AL BulgarieI, Tâlcuire la Faptele Apostolilor, trad. Grigorie Dascălul, transliterare Florin Stuparu, București, Edit. Sofia, 2007, p. 204.

27 Sfântul Maxim MĂRTURISITORUL, „Despre diferite locuri grele din Sfânta Scriptură”, întrebarea 31, în Filocalia, vol. 3, trad. Dumitru Stăniloae, București, Edit. Harisma, 1994, p. 128.

${ }^{28}$ Odiseea (XII, 297), apud Mircea ElIADE, Istoria ideilor și credințelor religioase, vol. 1, p. 278.

${ }^{29}$ Ibidem, p. 249. 
filozofilorca ,simbolul științei divine și al înțelepciunii umane" ${ }^{30}$. Ţinând cont de locul rostirii acestei cuvântări, în proximitatea templului Atenei, potrivit interpretării date de Sf. Maxim Mărturisitorul, Sf. Ap. Pavel ar fi spus: „Dumnezeu nu locuieşte într-un templu închinat înţelepciunii umane, ci în mintea curată, care este templul Înţelepciunii de la Dumnezeu".

În privința locuirii lui Dumnezeu, întrebarea retorică: „Oare

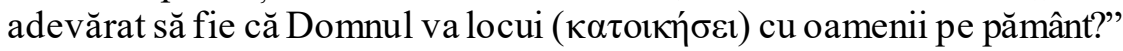
(3 Rg. 8, 27) - impune răspunsul: Nu. Dumnezeu poate viețui (oỉkźc) cu oamenii, dar locuința Lui (ca reședință) rămâne cerul.

Dumnezeu, fiind duh, nu are nevoie de un spațiu, ci locuiește acolo unde este sfințenie, adică în Biserică, iar ca aplicație particulară, locuiește în sufletul omenesc sau în mintea curată.

\subsection{De ce nu locuieşte Dumnezeu în temple făcute de mâini, ci în Templul duhovnicesc?}

Mai întâi, pentru că El, Creatorul, nu este condiționat de creație, ci El este Cel ce dă creaţiei ,viața și suflarea și toate” (Fap. 17, 25). Iar dacă omul are nevoie să fie ținut, nu poate el să-L susțină pe Dumnezeu, nici măcar cu ajutorul templelor - ,faptul este atât de evident, încât afirmarea lui devine aproape un truism (...), evident că nu ne putem gândi că El poate fi cuprins sau restrâns la o clădire făcută de om" 31 .

De asemenea, Dumnezeu nu poate să fie mărginit de creație. Omului i s-au pus hotare locuinței (Fap. 17, 26), dar omul nu-L poate limita pe Dumnezeu. Rugăciunea lui Solomon, prin cuvintele: ,cerurile cerurilor nu te pot cuprinde (...)", indică tocmai spre nelimitarea lui Dumnezeu.

Nu în ultimul rând, natura lui Dumnezeu este diferită de materie: „Nu trebuie să socotim dumnezeirea asemenea aurului sau argintului sau pietrei cioplite" (Fap. 17, 29). Iisus îi spune femeii samarinence că „Dumnezeu este Duh” (In. 4, 24), iar închinarea trebuie să țină seama de aspectul transcendenței Lui. Sf. Maxim Mărturisitorul vorbește despre

\footnotetext{
${ }^{30}$ Ibidem.

${ }^{31}$ David Gooding, Credincioși Adevărului. O nouă abordare a cărții Faptele Apostolilor, vol. 2, trad. Mirela Rădoi, Cluj-Napoca, Edit. Logos, 1995, p. 115.
} 
„neputința de a fi locaș al lui Dumnezeu [templul, n. ns.] din pricina materialității”32.

\section{3. Înțelegerea rolului locașului de închinare}

\subsection{Rol tipologic}

Prin cuvintele: „El se fălește numai cu figurile adevărului”’33, Sf. Maxim Mărturisitorul se referă la interpretarea tipologică a rostului Templului iudeu, ca locuință a lui Dumnezeu, și la confuzia iudeilor între Templu ca tip și adevărul pe care-l cuprinde. Templul nu era destinat ca locuință a lui Dumnezeu, ci era ,în cel mai bun caz, un simbol al realității”’34. Referindu-se la iudei, Sf. Maxim Mărturisitorul spune că (iudeul) ,a fost lipsit și de tip" 35 , deși ar fi putut beneficia din plin de „tiparele” prin care adevărul despre Dumnezeul imaterial sunt descoperite în materie.

Scriitorul Epistolei către Evrei, prin cuvintele: „Căci Hristos n-a intrat într-o Sfântă a Sfintelor făcută de mâini - închipuirea celei adevărate - ci chiar în cer" (Evr. 9, 24), arată că templul pământesc este doar un tip al adevăratului Templu, unde locuiește Dumnezeu. Părintele Stelian Tofană spune că ritualul săvârșitde arhiereul pământesc ,, a devenit tip”36, că ,ritualul vechi constituie, spune el, «o pildă», o reprezentare figurată (...) ${ }^{337}$, precum spune și Sf. Ioan Gură de Aur:„,Prin urmare acestea sunt adevărate, iară acele tipuri, că şi templul aşa s-au întocmit, ca cerul cerului'”38.

Așadar, un locașdeînchinare pământesc poate prezenta tipologic ceea ce se întâmplă în cer, în lumea spirituală, iar înțelegerea trebuie să treacă dincolo de materialitatea tipului, spre realitatea pe care acestea o exprimă.

\subsection{Rol catehetic}

Un locaș de închinare trebuie să ajute învățarea despre Dumnezeul pe Care Îl reprezintă.

${ }^{32}$ Sf. Maxim Mărturisitorul, Filocalia, vol. 3, p. 128.

${ }^{33}$ Ibidem, p. 129.

${ }^{34}$ David Gooding, Credincioși Adevărului, vol. 2, p. 116.

${ }^{35}$ Sf. Maxim Mărturisitorul, Filocalia, vol. 3, p. 129.

${ }^{36}$ Stelian Tofană, Iisus Hristos Arhiereu veșnic - după Epistola către Evrei, p. 363.

${ }^{37}$ Ibidem, p. 362.

${ }^{38}$ Ioan Chrisostom, Comentariile sau Explicarea Epistolei Cătră Ebrei, p. 226. 
În cazul templelor idolești, acestea puteau învăța despre zei asemenea oamenilor, dar cu puteri mai mari, puteri ce-i făceau uneori capricioși.

În cazul clădirilor bisericii, rolul catehetic se înfăptuiește prin activitatea catehetică a preotului sau a ierarhului, clădirea bisericii füind locul întâlnirii și învățării credincioșilor. Sf. Ioan Gură de Aur încurajează construirea locașurilor de cult folositoare pentru învățarea credincioșilor, spunând: „Clădirea este a Bisericii (...) și tu vei fi pricina celor ce se catehizează acolo, în ținuturile din apropiere"39.

Apoi, putem vorbi de „lumina din interior”. Viața credincioșilor, crescuți spiritual prin participarea la slujbă, devine „lumina lumii”. De asemenea, arta bisericească are rol catehetic. Pe lângă „lumina” din ochii celor pictați, viața lor este exemplu de urmat. Scenele din viaţa Mântuitorului, picturile cu Profeții, cu Martirii și cu Sfinții, sunt imagini care ajută catehetic, știut fiind că informația vizuală este mai ușor receptată decât cea auzită, iar în biserică ele se completează reciproc.

Pe lângă lumina din interior, cu rol catehetic, putem vorbi, în unele cazuri, de o arhitectură care vorbeşte despre lumina din exterior, adică de sus. Ca un exemplu particular, în biserica monument Unesco din Pătrăuți, Suceava, la anumite date din calendarul bisericesc, lumina soarelui, pătrunsă prin geam sau pe ușă, cade exact pe scenele pictate, care vorbesc despre sărbătoarea respectivă. Iar dacă avem de-a face și cu o astfel de arhitectură, este evident că la construirea bisericii s-au facut lucrări magnifice, care să comunice, fără glas, că Dumnezeu îi învață și îi conduce pe credincioși cu lumina Sa. Ca o concluzie preliminară a cercetării sale, Gabriel Herea afirmă: „Pentru mine a fost clar: proiecțiile solare de la Pătrăuți nu sunt întâmplătoare!'40, constatare la care ajunge și în urma altor cercetări ${ }^{41}$, în domeniul artei medievale bisericești.

${ }^{39}$ Sf. Ioan GurĂ DE Aur, Comentariu la Faptele Apostolilor, trad. Lavrentie Carp, Iași, Edit. Doxologia, 2016, p. 249.

${ }^{40}$ Gabriel Herea, Tudor Călin Urcan, Păzitorii pragului la Pătrăuți, București, Edit. Meteor Publishing, 2018, p. 56.

41 O lucrare mai amplă, rezultată din cercetarea lui Gabriel Herea, este: Mesajul Eshatologic al spațiului liturgic creștin. Arhitectură și icoană în Moldova secolelor $X V$-XVI, editată în anul 2013. 


\subsection{Rol sacramental}

Ca spațiu de închinare comunitară, cel ce slujeşte la altar este în partăşie cu altarul: „Cei ce mănâncă jertfele nu sunt ei, oare, părtași altarului?" (1 Cor. 14, 19), întreabă retoric Sf. Ap. Pavel în contextul afirmației despre Euharistie ca loc al prezenței lui Hristos.

De asemenea, locaşul de închinare este un loc potrivit pentru rugăciune. Rugăciunea în locașul Bisericii găsește împlinire, „nu pentru că Dumnezeu stă într-un loc pământesc unde te ascultă" ${ }^{42}$, ci pentru că rugăciunea sporește prin comuniunea cu alți credincioși care se roagă. Fericitul Augustin spunea: „Vino la biserică, ca să ți se întărească râvna în rugăciune,(...)”43. În modestia sa, regele Solomon recunoaște că templul pe care vrea să-l zideascănu-L poateîncăpea pe Dumnezeu, „,ără numai doar pentru a se tămâia înainteaLui" (2 Par. 2,6). Asocierea dintre tămâiere și rugăciune este un motiv întâlnit în Psaltire: „Să se îndrepteze rugăciunea mea ca tămâia înaintea ta" (Ps. 140, 2) - și, de asemenea, cartea Apocalipsa vorbește în mod repetat despre „, cupe de aur pline cu tămâie care sunt rugăciunile sfinților" (Apoc. 5, 8; 8, 3-4). Această afirmație conduce inevitabil spre cuvântul Mântuitorului: „Scris este: «Casa Mea, casă de rugăciune se va chema»"(Mt. 21, 13).

\section{Concluzii}

1. Afirmația Sf. Ap. Pavel în Areopag: „Dumnezeu (...) nu locuiește în temple făcute de mâini”, deși are la bază învățătura vetero testamentară, se adresează cu precădere păgânilordin Atena, dar este o învățătură folositoare nu doar păgânilor, ci și evreilor și creștinilor.

2. Prezentul studiu subliniază că locuința lui Dumnezeu, ca reședință, este cerul. Însă, locuința lui Dumnezeu, ca viețuire prin Duhul, este Biserica, Templul duhovnicesc, iar la modul individual, potrivit afirmației Sf. Maxim Mărturisitorul, locuința lui Dumnezeu este mintea curată.

3. Adevărul proclamat de Sf. Ap. Pavel: „Dumnezeu (...) nu locuiește în temple făcute de mâini”, deși provocator, nu

\footnotetext{
${ }^{42}$ Fericitul Augustin, Predici la marile sărbători, vol. I, trad. Corneliu Clop, București, Edit. Basilica a Patriarhiei Române, 2004, p. 206.

${ }^{43}$ Ibidem.
} 
demontează, ci clarifică rolul unui locaș de închinare, tipologic, catehetic și sacramental, pentru zidirea Bisericii lui Hristos, loc al viețirii lui Dumnezeu prin Duhul, Biserica devenind astfel „stâlp și temelie a adevărului” (1 Tim. 3,15).

4. Importanța majoră a acestei teme reclamă o dezvoltare viitoare a ei, mai ales în privința templului duhovnicesc, dar și în privinţa rolului clădirilor ca locașuri de închinare.

\section{Referinţe bibliografice:}

1. BIBLIA, București, Edit. Institutului Biblic şi de Misiune al Bisericii Ortodoxe Române, 1988;

2. ALAND, Barbara and Kurt (eds.), Novum Testamentum Graece, Stuttgart, Deutsche Bibelgesellschaft, 2013;

3. Fericitul Augustin, Predici la marile sărbători, vol. I, trad. Corneliu Clop, București, Edit. Basilica a Patriarhiei Române, 2004;

4. FILOCALIA, vol. 3, trad. Dumitru Stăniloae, București, Edit. Harisma, 1994;

5. BAȘTOVOI, Sa vatie, Pietrele vorbesc, București, Edit. Cathisma, 2014;

6. BocK, Darell L., Acts, Grand Rapids, Edit. Baker Academic, 2007;

7. BRUCE, Frederick Fyvie, Commentary on the Book of the Acts, Grand Rapids, Edit. Eerdmans Publishing Company, 1980;

8. Chrisostom, Ioan, Comentariile sau Explicarea Epistolei Cătră Ebrei, trad. Theodosie Athanasiu, București, Edit. Tipografia Cărților Bisericești, 1923;

9. Douglas, James D. (ed.), The New Bible Dictionary, London, Edit. The Inter-Varsity Fellowship, 1962;

10. DRIMBA, Ovidiu, Istoria Culturii și Civilizației, vol. 1, București, Edit. Ştiințifică și Enciclopedică, 1985;

11. ELIADE, Mircea, Istoria ideilor și credințelor religioase, vol. 1, București, Edit. Științifică, 1991;

12. GILL, David W. J. / GEMPF, Conrad, (eds.), The Book of Acts in Its Graeco-Roman Setting, Grand Rapids, Edit. William B. Eerdmands Publishing Company, 1994;

13. Gooding, David, Credincioși Adevărului. O nouă abordare a cărții Faptele Apostolilor, vol. 2, trad. Mirela Rădoi, Cluj-Napoca,Edit. Logos, 1995; 
14. Herea, Gabriel / UrCan, Tudor Călin, Păzitorii pragului la Pătrăuți, București, Edit. Meteor Publishing, 2018;

15.Sf. IOAN GURĂ de AUR, Comentariu la Faptele Apostolilor, trad. Lavrentie Carp, Iași, Edit. Doxologia, 2016;

16. Rossé, Gérard, Faptele Apostolilor, trad. Silvestru-Robert Bălan, Iaşi, Edit. Sapientia, 2016;

17. STOIAN, Ioan M., Dicționar religios, București, Edit. Garamond, 1994;

18. Sf. TEOFILACT alBulgariei, Tâlcuire la Faptele Apostolilor, trad. Grigorie Dascălul, transliterare Florin Stuparu, București, Edit. Sofia, 2007;

19. TERINTE, Cristian-Fla vius, Viața Bisericii conform metaforelor pauline, Oradea, Edit. Societatea Biblică din România, 2010;

20. TofanĂ, Stelian, Iisus Hristos Arhiereu veșnic - după Epistola către Evrei, Cluj-Napoca, Edit. Presa Universitară Clujeană, 2000;

21. Vernant, Jean-Pierre, Mitși gândire în Grecia Antică, trad. Zoe Petre și Andrei Niculescu, București, Edit. Meridiane, 1995. 